\title{
Электронные свойства приповерхностных квантовых ям InGaAs/InAIAs c инвертированным легированием на подложках InP
}

\author{
(C) Г.Б. Галиев ${ }^{1}$, А.Н. Клочков ${ }^{1, \uparrow}$, И.С. Васильевский ${ }^{2}$, Е.А. Климов ${ }^{1}$, С.С. Пушкарев ${ }^{1}$, \\ А.Н. Виниченко ${ }^{2}$, Р.А. Хабибуллин ${ }^{1}$, П.П. Мальцев ${ }^{1}$ \\ ${ }^{1}$ Институт сверхвысокочастотной полупроводниковой электроники Российской академии наук, \\ 117105 Москва, Россия \\ ${ }^{2}$ Национальный исследовательский ядерный университет „МИФИ“, \\ 115409 Москва, Россия \\ ฯ E-mail: klochkov_alexey@mail.ru
}

(Получена 22 ноября 2016 г. Принята к печати 28 ноября 2016 г.)

\begin{abstract}
Сравниваются электронные транспортные и оптические свойства гетероструктур с приповерхностной квантовой ямой InGaAs/InAlAs при использовании инвертированного (снизу от квантовой ямы) и стандартного (сверху от квантовой ямы) $\delta$-легирования атомами $\mathrm{Si}$. Показано, что при использовании инвертированного легирования происходит увеличение плотности двумерных электронов в квантовой яме по сравнению со стандартным расположением легирующего слоя при идентичных составах и толщинах других слоев гетероструктур. Наблюдаемые особенности низкотемпературного электронного транспорта (осцилляций Шубникова-де-Гааза, эффекта Холла) и спектров фотолюминесценции гетероструктур интерпретированы с помощью моделирования зонной структуры.
\end{abstract}

DOI: 10.21883 /FTP.2017.06.44559.8456

\section{1. Введение}

$\delta$-Легированные через спейсер наногетероструктуры с квантовой ямой (КЯ) InGaAs/InAlAs на подложках фосфида индия (InP) используются в качестве материала для полевых транзисторов HEMT (high electron mobility transistor) в СВЧ электронике миллиметрового диапазона длин волн [1,2]. В последнее время продемонстрирована работа НЕМТ на частотах свыше 1 ТГц, достигнутых за счет миниатюризации элементов транзисторов и уменьшения длины затворов до десятков нанометров [3,4]. Для предотвращения короткоканальных эффектов и увеличения крутизны в таких НЕМТ аспектное отношение (отношение длины затвора $L_{g}$ к глубине залегания КЯ $\left.L_{b}\right)$ должно составлять $L_{g} / L_{b}>5$. Таким образом, узкозонный слой КЯ InGaAs должен располагаться как можно ближе к поверхности гетероструктуры, на глубине $\sim 10$ нм $[5,6]$. При снижении толщины барьерного слоя InAlAs менее 10 нм увеличивается туннельная прозрачность барьера, что негативно влияет на токи утечки и напряжение пробоя [7]. Легирующий донорный слой, который в стандартных структурах InGaAs/InAlAs располагается между КЯ и поверхностью, создает потенциальную яму для электронов и дополнительно понижает высоту потенциального барьера InAlAs. Кроме того, становится возможным туннелирование электронов через донорные состояния в барьере InAlAs. В этом случае резонным становится переход к инвертированному легированию КЯ через спейсер InAlAs снизу от КЯ [8-10].

Различие электронных свойств стандартных и инвертированных гетероструктур было обнаружено для гетеропереходов GaAs/AlGaAs, в которых подвижность электронов в инвертированных структурах существенно ниже при использовании одинаковых условий эпитаксиального роста $[11,12]$. Это объясняется различной шероховатостью прямой и обратной гетерограниц, а также сегрегацией легирующих примесей в слой GaAs из барьера при инвертированном легировании. Для повышения подвижности электронов в инвертированных структурах $\mathrm{GaAs} / \mathrm{AlGaAs}$ было предложено снижать температуру роста спейсера [13], использовать прерывания роста [14], создавать сверхрешеточный спейсер [15]. Аналогично для HEMT-гетероструктур с КЯ InGaAs/InAlAs на подложках InP подвижность электронов в инвертированных структурах меньше по сравнению со стандартным расположением легирующего слоя [16], что связано с примесным рассеянием из-за сегрегации атомов $\mathrm{Si}$ в КЯ из легированной области InAlAs [17]. Путем оптимизации эпитаксиального роста, например увеличения толщины спейсера [18] либо снижения температуры роста спейcepa InAlAs до $300^{\circ} \mathrm{C}$ [19], подвижность электронов в инвертированных структурах может быть приближена к подвижности в стандартных структурах.

В цитированных работах были исследованы электронные свойства гетероструктур InGaAs/InAlAs, в которых КЯ размещена на значительном удалении от поверхности - более 50 нм, а приповерхностный защитный слой InGaAs легирован донорами для экранирования влияния поверхностного потенциала на состояния электронов в КЯ. Цель данной работы состоит в исследовании особенностей электронных транспортных и оптических свойств инвертированных гетероструктур с приповерхностным расположением КЯ $\mathrm{In}_{0.53} \mathrm{Ga}_{0.47} \mathrm{As} / \mathrm{In}_{0.52} \mathrm{Al}_{0.48} \mathrm{As}$, наиболее соответствующих СВЧ-транзисторам миллиметрового диапазона. 
Таблица 1. Схема гетероструктур

\begin{tabular}{c|c}
\hline $\begin{array}{c}\text { Стандартная структура } \\
\text { (образцы 308, 312) }\end{array}$ & $\begin{array}{c}\text { Инвертированная структура } \\
\text { (образцы } 309,313)\end{array}$ \\
\hline $\mathrm{In}_{0.53} \mathrm{Ga}_{0.47} \mathrm{As}(4.6 \mathrm{Hм})$ \\
\hline \multicolumn{2}{c}{ Барьер $\mathrm{In}_{0.52} \mathrm{Al}_{0.48} \mathrm{As}(14.3 \mathrm{HM})$} \\
\hline$\delta$ - $\mathrm{Si}\left(N_{\mathrm{Si}}\right)$ & КЯ $\mathrm{In}_{0.53} \mathrm{Ga}_{0.47} \mathrm{As}(15 \mathrm{HM})$ \\
\hline $\mathrm{In}_{0.52} \mathrm{Al}_{0.48} \mathrm{As}(5.8 \mathrm{HM})$ & $\mathrm{In}_{0.52} \mathrm{Al}_{0.48} \mathrm{As}(5.8 \mathrm{HM})$ \\
\hline КЯ $\mathrm{In}_{0.53} \mathrm{Ga}_{0.47} \mathrm{As}(15 \mathrm{HM})$ & $\delta$-Si \\
\hline \multicolumn{2}{c}{$\mathrm{In}_{0.52} \mathrm{Al}_{0.48} \mathrm{As}(345 \mathrm{HM})$} \\
\hline
\end{tabular}

Подложка $\operatorname{InP}(100)$

\section{2. Образцы и методы исследования}

Исследуемые образцы представляют собой гетероструктуры с наноразмерной КЯ InAlAs/InGaAs/InAlAs, односторонне $\delta$-легированные кремнием. Слоевая структура образцов, представленная в табл. 1, была следующей: полуизолирующая подложка $\operatorname{InP}(100)$, буферный слой $\mathrm{In}_{0.52} \mathrm{Al}_{0.48} \mathrm{As}$ толщиной $345 \mathrm{HM}$, КЯ $\operatorname{In}_{0.53} \mathrm{Ga}_{0.47} \mathrm{As}$ (15 нм) со спейсером $\operatorname{In}_{0.52} \mathrm{Al}_{0.48} \mathrm{As}(5.8 \mathrm{Hм})$ со стандартным или инвертированным $\delta$-легированием, барьерный слой $\operatorname{In}_{0.52} \mathrm{Al}_{0.48} \mathrm{As}(14.3 \mathrm{HM})$, защитный слой $\mathrm{In}_{0.53} \mathrm{Ga}_{0.47} \mathrm{As}$ (4.6 нм). Две пары образцов (308/309 и 312/313), в которых один образец - стандартная, а второй - инвертированная НЕМТ-гетероструктура, различались концентрацией доноров в $\delta$-слое и некоторыми технологическими условиями эпитаксиального роста: температурой роста, парциальным давлением мышьяка $\mathrm{As}_{4}$ при росте и температурой роста спейсера (табл. 2).

Образцы были выращены методом молекулярнолучевой эпитаксии на установке Riber Compact $21 \mathrm{~T}$. Температура роста буфера составляла $510^{\circ} \mathrm{C}$ для пары 308/309 и 515 ${ }^{\circ} \mathrm{C}$ для пары 312/313. Для предотвращения сегрегации $\mathrm{Si}$ в КЯ инвертированных структур температура подложки перед ростом спейсера $\operatorname{In}_{0.52} \mathrm{Al}_{0.48} \mathrm{As}$ понижалась до $350^{\circ} \mathrm{C}$ для образца 309 и до $380^{\circ} \mathrm{C}$ для образца 313. Для сохранения идентичности условий формирования гетерограницы спейсер/КЯ температура роста спейсера аналогично понижалась и для стандартных гетероструктур 308 и 312.

Образцы для исследования электронных транспортных свойств были изготовлены при помощи фотолитографии и жидкостного травления мезы в форме холловских мостиков. Омические контакты были сформированы взрывной литографией и вакуумной металлизацией $\mathrm{Ni} / \mathrm{AuGe} / \mathrm{Ni} / \mathrm{Au}$ с последующим щадящим вжиганием при температуре $350^{\circ} \mathrm{C}$ в течение 1 мин. Концентрация и подвижность электронов в КЯ образцов определялись по измерениям электропроводности и эффекта Холла при температурах 300, 77 и 4.2 К. При низких температурах в квантующем магнитном поле до 6 Тл исследовался эффект Шубникова-де-Гааза и эффект Холла на установке CryoFree8 с прецизионным терморегулятором Lakeshore 335.

Измерения спектров фотолюминесценции (ФЛ) образцов проводились в оптическом криостате при температуре $79 \mathrm{~K}$ в атмосфере азота. Для возбуждения ФЛ использовался Не-Ne-лазер мощностью 50 мВт с энергией фотонов 1.96 эВ. Для регистрации спектров использовался неохлаждаемый фотодиод Hamamatsu G8372-01 на основе InGaAs.

\section{3. Моделирование зонной структуры}

Поверхностные состояния играют значительную роль в формировании зонного профиля в модулированнолегированных гетероструктурах с приповерхностными КЯ [20]. Высокая плотность поверхностных состояний, расположенных по энергии вблизи середины запрещенной зоны, приводит к закреплению уровня Ферми на поверхности при энергиях поверхностной зоны [21]. В результате заполнения поверхностных состояний формируется обедненная электронами область между поверхностью гетероструктуры и КЯ, в которой присутствует достаточно сильное электрическое поле. При приближении КЯ с двумерным электронным газом к поверхности влияние поверхностных состояний в гетероструктуре должно становиться все более заметным, приводя к истощению электронной плотности в КЯ и изменению оптических и транспортных электронных свойств гетероструктур из-за искажения потенциала КЯ поверхностным электрическим полем [22].

Для моделирования влияния инвертированного легирования и толщины барьерного слоя InAlAs на зонную структуру на энергии $E_{i}$ и волновые функции (ВФ) $\Psi_{i}$ двумерных электронных подзон и на распределение электронного заряда в КЯ InGaAs/InAlAs проводилось численное решение системы уравнений Шредингера-Пуассона в приближении эффективной массы [23]. Использовались следующие значения параметров полупроводников: эффективная масса электронов $\quad 0.043 m_{0}$ для $\operatorname{In}_{0.53} \mathrm{Ga}_{0.47} \mathrm{As} \quad$ и $\quad 0.073 m_{0}$ для $\mathrm{In}_{0.52} \mathrm{Al}_{0.48} \mathrm{As}$, разрыв края зоны проводимости на границе $\mathrm{In}_{0.53} \mathrm{Ga}_{0.47} \mathrm{As} / \mathrm{In}_{0.52} \mathrm{Al}_{0.48} \mathrm{As}$ был равен 0.51 эB $[24,25]$. На поверхности гетероструктур положение уровня Ферми полагалось на 0.25 эВ ниже края зоны проводимости $\mathrm{In}_{0.53} \mathrm{Ga}_{0.47} \mathrm{As}$ [26]. Расчеты проводились для температур 300 и $4.2 \mathrm{~K}$.

Зонные диаграммы гетероструктур со стандартным (образец 308) и инвертированным (образец 309) легированием (при $T=4.2 \mathrm{~K}$ ) приведены на рис. 1, $a$ и $b$ соответственно. Уровень Ферми совпадает с нулем энергии. Наиболее сильно изменение расположения доноров сказывается на энергии дна зоны проводимости в окрестности $\delta$-слоя. Встроенное электрическое поле в гетероструктуре влияет на кривизну дна КЯ и расположение максимума электронной волновой функции основного состояния. Электроны в КЯ стандартных и инвертированных гетероструктур локализуются соответственно 
Таблица 2. Условия эпитаксиального роста (температура роста $T_{g}$, температура роста спейсера $T_{\mathrm{sp}}$, поток мышьяка $P_{\text {Аs}}$, концентрация легирования $N_{\delta \text {-Si }}$ ) и электрофизические характеристики образцов (концентрация $n_{S}$ и подвижность $\mu_{e}$ электронов)

\begin{tabular}{|c|c|c|c|c|c|c|c|c|}
\hline \multirow{2}{*}{$\begin{array}{c}\text { Образец, } \\
\text { тип структуры }\end{array}$} & \multirow{2}{*}{$\begin{array}{l}T_{g}, \\
{ }^{\circ} \mathrm{C}\end{array}$} & \multirow{2}{*}{$\begin{array}{c}T_{s p}, \\
{ }^{\circ} \mathrm{C}\end{array}$} & \multirow{2}{*}{$\begin{array}{c}P_{\text {As, }} \\
\text { мкТорр }\end{array}$} & \multirow{2}{*}{$\begin{array}{c}N_{\delta-\mathrm{Si}} \\
10^{12} \mathrm{~cm}^{-2}\end{array}$} & \multicolumn{2}{|c|}{$\mu_{e}, \mathrm{~cm}^{2} /(\mathrm{B} \cdot \mathrm{c})$} & \multicolumn{2}{|c|}{$n_{S}, 10^{12} \mathrm{~cm}^{-2}$} \\
\hline & & & & & $300 \mathrm{~K}$ & $77 \mathrm{~K}$ & $300 \mathrm{~K}$ & $77 \mathrm{~K}$ \\
\hline 308 (стандартная) & 515 & 350 & 30 & 3.6 & 9540 & 35410 & 1.45 & 1.38 \\
\hline 309 (инвертированная) & 515 & 350 & 30 & 3.6 & 8360 & 22180 & 2.83 & 2.82 \\
\hline 312 (стандартная) & 510 & 380 & 25 & 2.7 & 7520 & 25650 & 0.86 & 0.83 \\
\hline 313 (инвертированная) & 510 & 380 & 25 & 2.7 & 8000 & 20160 & 2.08 & 2.04 \\
\hline
\end{tabular}
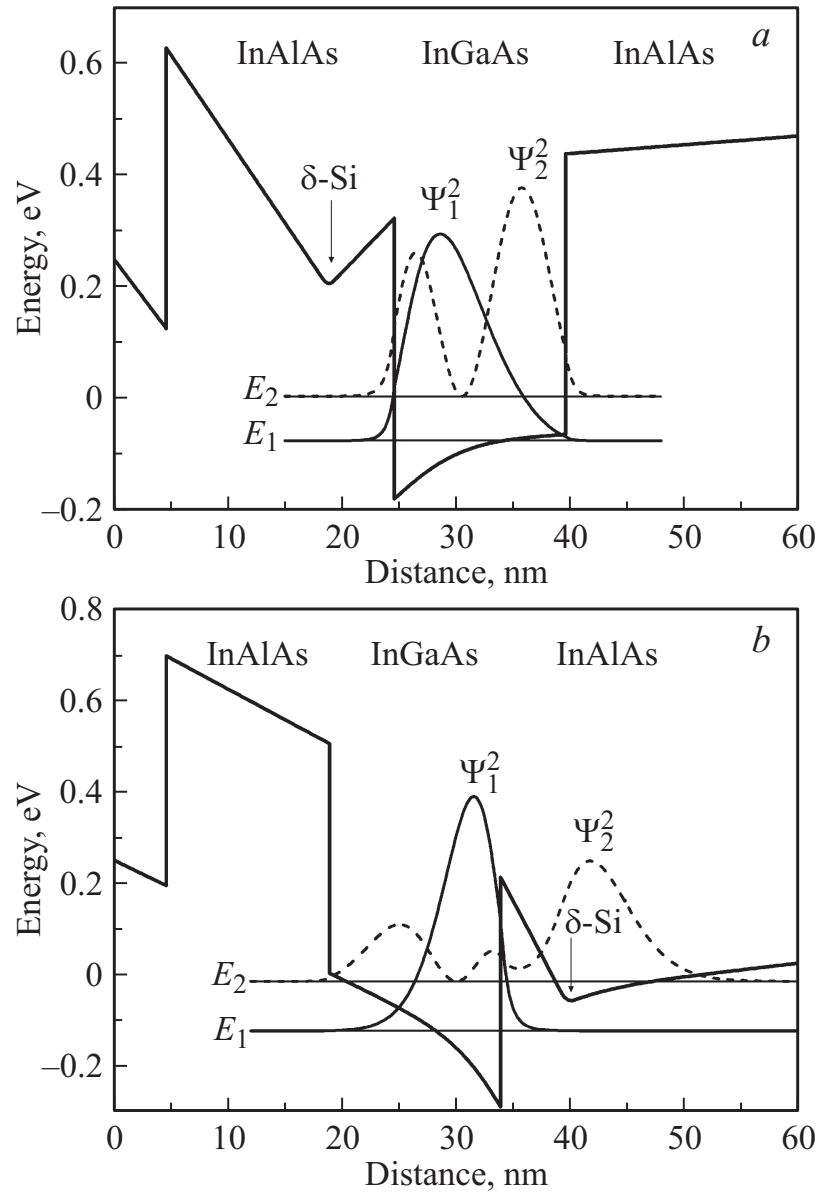

Рис. 1. Зонные диаграммы гетероструктур 308 со стандартной геометрией легирования $(a)$ и 309 с инвертированным легированием $(b), E_{\mathrm{C}}-$ пространственный профиль края зоны проводимости, $E_{1}$ и $E_{2}-$ энергии, $\Psi_{1}^{2}$ и $\Psi_{2}^{2}-$ квадраты ВФ электронов в первой и второй подзонах размерного квантования.

y верхней и нижней гетерограниц InGaAs/InAlAs за счет действия электрического поля ионизированных доноров. Дополнительная асимметрия зонного профиля вносится потенциалом поверхностных состояний. При стандартном (верхнем) легировании электрические поля поверхностных состояний и легирующих примесей в области КЯ вычитаются, а при инвертированном легировании - складываются. Поэтому, как видно на рис. $1, b$, при инвертированном легировании распределение заряда в КЯ более несимметрично: максимум электронной плотности в гетероструктуре 308 располагается на расстоянии 4.1 нм от ближайшей гетерограницы, а в гетероструктуре 309 - на расстоянии 2.3 нм. Таким образом, в инвертированных гетероструктурах амплитуда ВФ электронов вблизи правой гетерограницы InGaAs/InAlAs оказывается выше. Кроме того, ввиду меньшей потенциальной энергии в барьере-спейсере увеличивается туннельное проникновение электронов нижней подзоны КЯ в барьер InAlAs (в область расположения доноров), а также существенно изменяется форма ВФ электронов во 2-й подзоне (рис. 1). Таким образом, в инвертированной структуре можно ожидать снижения подвижности электронов из-за возрастания рассеяния на ионизированной примеси и шероховатостях гетерограницы.

Из-за различного расположения легирующего слоя по отношению к КЯ и поверхности возникает также отличие в концентрации электронов при стандартном и инвертированном способах легирования. На рис. 2 приведены рассчитанные для $T=300 \mathrm{~K}$ зависимости двумерной концентрации электронов $n_{S}$ в КЯ от толщины барьерного слоя InAlAs $L_{b}$ для двух концентраций легирования $\mathrm{Si}$ в $\delta$-слое $N_{\mathrm{Si}}=3.6 \cdot 10^{12}$ и $2.7 \cdot 10^{12} \mathrm{~cm}^{-2}$,

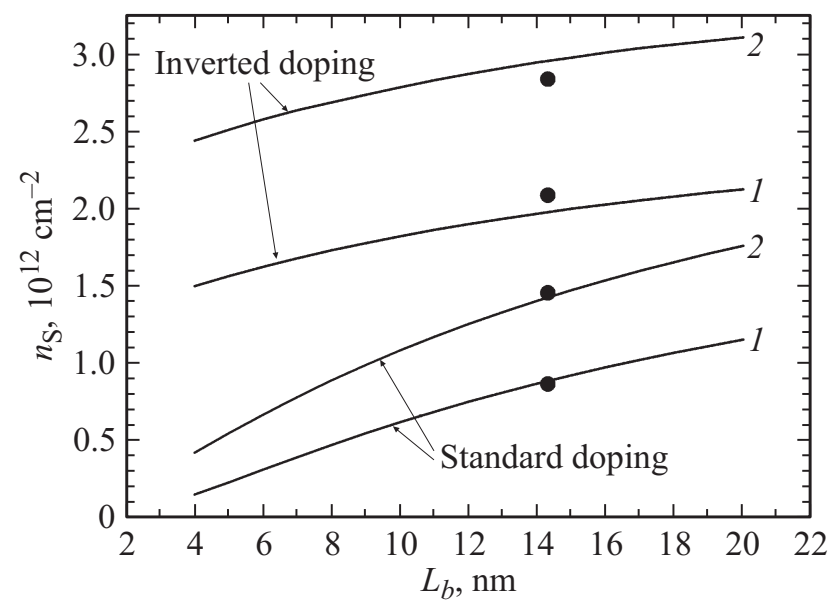

Рис. 2. Рассчитанная зависимость двумерной концентрации электронов $n_{S}$ от толщины барьерного слоя $L_{b}$ для стандартных и инвертированных гетероструктур с различным уровнем легирования: $1-N_{\mathrm{Si}}=2.7 \cdot 10^{12} \mathrm{~cm}^{-2}, 2-$ $N_{\mathrm{Si}}=3.6 \cdot 10^{12} \mathrm{~cm}^{-2}$; точки - экспериментальные значения. 
соответствующих парам образцов 308/309 и 312/313. Конструкция гетероструктур соответствует табл. 1. Видно, что рассчитанная концентрация электронов в КЯ для случая инвертированного легирования в $2-3$ раза выше, чем для стандартного при прочих равных условиях: сохранении состава, уровня легирования и расположения других слоев гетероструктур. Отличие в концентрации электронов для двух способов легирования возрастает при приближении КЯ к поверхности. Это различие является следствием обеднения КЯ за счет влияния поверхностного потенциала, за счет смещения центроида электронного газа и легирующей области $\delta$-Si от поверхности для инвертированных структур на величину, сопоставимую с шириной КЯ. Данный эффект особенно проявляется при малой глубине залегания КЯ.

\section{4. Экспериментальные результаты}

\section{1. Электронный транспорт}

Измеренные с помощью эффекта Холла электронные транспортные свойства образцов (подвижность $\mu_{e}$ и концентрация $n_{S}$ двумерного электронного газа) представлены в табл. 2. Видно, что измеренная холловская концентрация электронов в инвертированно-легированных образцах больше, чем в стандартных, что находится в хорошем согласии с зонным расчетом (рис. 2). Подвижность электронов при $77 \mathrm{~K}$ в парах образцов 308/309 и 312/313 уменьшается при переходе от стандартного легирования к инвертированному.

Во всех образцах при гелиевых температурах наблюдаются осцилляции магнетосопротивления (эффект Шубникова-де-Гааза) (см. рис. 3). При этом в образцах 308,312 и 313 наблюдается одна частота осцилляций, а в образце 309 проявляются слабые низкочастотные осцилляции, связанные с заполнением электронами второй подзоны размерного квантования. Интересно отметить, что низкочастотные осцилляции в образце 309 начинаются практически в том же магнитном поле, что и высокочастотные. Для анализа концентраций электронов в подзонах размерного квантования КЯ были определены частоты по фурье-анализу амплитуды магнетосопротивления относительно обратной магнитной

Таблица 3. Результаты криомагнитных $(T=4.2 \mathrm{~K})$ измерений с помощью методов Холла (подвижность $\mu_{e}$, концентрация $n_{S}$, удельное сопротивление $\left.\rho_{S}\right)$ и Шубникова-де-Гааза (концентрация электронов в подзонах $n_{\mathrm{SdH}}$ )

\begin{tabular}{l|c|c|c|c}
\hline \multicolumn{1}{c|}{ Образец } & $\begin{array}{c}\mu_{e}, \\
\mathrm{~cm}^{2} /(\mathrm{B} \cdot \mathrm{c})\end{array}$ & $\begin{array}{c}n_{S}, \\
10^{12} \mathrm{~cm}^{-2}\end{array}$ & $\begin{array}{c}n_{\mathrm{SdH}}, \\
10^{12} \mathrm{~cm}^{-2}\end{array}$ & $\begin{array}{c}\rho_{S}, \\
\mathrm{OM} / \square\end{array}$ \\
\hline 308 (стандартный) & 48870 & 1.43 & 1.45 & 89.3 \\
309 (инвертированный) & 17610 & 3.15 & 2.83 & 112.5 \\
312 (стандартный) & 36340 & 1.13 & 1.14 & 152 \\
313 (инвертированный) & 27320 & 2.29 & 2.32 & 100
\end{tabular}

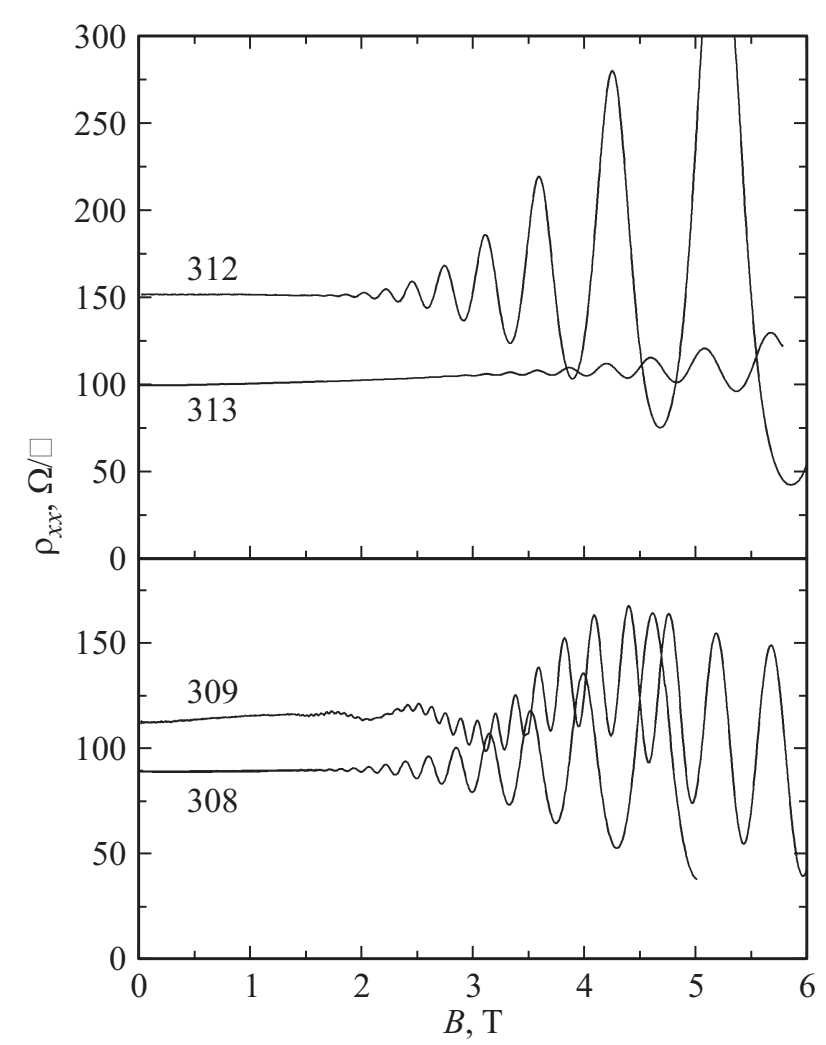

Рис. 3. Осцилляции магнетосопротивления в образцах при температуре $T=4.2 \mathrm{~K}$.

индукции. Концентрации электронов, определенные из эффекта Холла и эффекта Шубникова-де-Гааза, хорошо соответствуют друг другу (в случае образца 308 сумма концентраций в двух подзонах) (см. табл. 3).

Обсудим причину снижения подвижности электронов в парах образцов 308/309 и 312/313 при использовании инвертированного легирования. Для каждой пары концентрация атомов $\mathrm{Si}$ в $\delta$-слое была одинаковой. Эффект экранирования примесного потенциала двумерными электронами должен приводить к снижению примесного рассеяния при возрастании концентрации, т. е. подвижность электронов, обусловленная примесным рассеянием, должна быть больше для инвертированных структур с большим $n_{S}$. При сравнении структур 308 и 312 одного типа такое поведение подтверждается экспериментом. Однако в паре образцов 309/313 наблюдается уменьшение холловской подвижности с ростом концентрации электронов. При этом для всех образцов температура роста спейсера была существенно меньше принятых значений для HEMT на подложках InP, и потому сегрегация атомов $\mathrm{Si}$ в область КЯ при инвертированном легировании была затруднена.

Главной причиной снижения подвижности в инвертированных структурах является изменение зонной структуры (см. разд. 3). Значительное уменьшение высоты барьера КЯ со стороны донорного слоя в КЯ с инвертированным легированием приводит к возрастанию амплитуды ВФ электронов в барьере и, следовательно, 


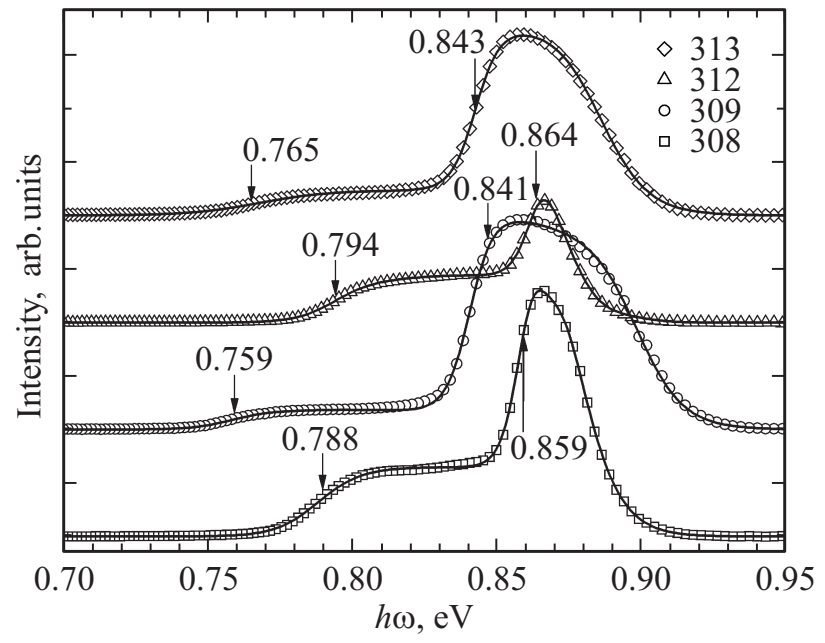

Рис. 4. Спектры ФЛ образцов при $77 \mathrm{~K}$; точки - эксперимент, кривые - результат подгонки, стрелками отмечены энергии переходов, соответствующие доньям двумерных квантовых подзон.

к увеличению рассеяния электронов на ионизированных донорах. Кроме того, асимметрия дна КЯ вызывает смещение ВФ электронов и приближение электронов к гетерогранице InGaAs/InAlAs, приводящее к возрастанию рассеяния электронов. Отметим, что для второй подзоны размерного квантования изменения энергии и структуры электронной волновой функции еще более существенны - в КЯ со стандартным легированием ВФ $\Psi_{2}$ локализована в КЯ InGaAs, а в КЯ с инвертированным легированием $\Psi_{2}$ имеет „гибридный“ характер и принадлежит как слою КЯ, так и барьеру InAlAs, включая область расположения доноров. В этом случае увеличивается рассеяние электронов во второй подзоне и можно ожидать снижение холловской подвижности. Именно этот фактор холловского усреднения по двум электронным подзонам с различной подвижностью электронов, по нашему мнению, приводит к сниженной величине холловской подвижности в образце 309 с двумя заполненными подзонами размерного квантования.

\section{2. Спектроскопия ФЛ}

Низкотемпературные спектры ФЛ от КЯ InGaAs/ InAlAs, измеренные при $79 \mathrm{~K}$, представлены на рис. 4. Для всех образцов наблюдаются две линии ФЛ, которые соответствуют переходам из первой и второй электронных подзон в первую подзону тяжелых дырок $e 1-h 1$ и $e 2-h 1$. Для образцов 308,312 и 313 с одной заполненной электронной подзоной переходы $e 2-h 1$ наблюдаются за счет фотозаполнения второй подзоны возбуждающим лазером.

При переходе от стандартного к инвертированному легированию изменяется форма спектров ФЛ и возрастает интенсивность перехода $e 2-h 1$ по отношению к $e 1-h 1 \quad\left(I_{e 1-h 1} / I_{e 2-h 1}\right.$ составляет для пары образцов $308 / 309-3.6$ и 10.7, для пары $312 / 313$ - 2.7 и 7.8). Это изменение относительной интенсивности оптических переходов обычно связано с двумя факторами. Первое - изменение перекрытия ВФ электронов и дырок и матричного элемента оптического перехода из-за изменения изгиба дна КЯ. Второе - изменение соотношения концентраций электронов в двух подзонах. Как следует из разд. 3, при переходе от стандартного к инвертированному легированию возрастает электрическое поле в области КЯ и увеличивается заполнение второй электронной подзоны. Первый фактор приводит к относительному снижению интенсивности перехода $e 1-h 1$, а второй - к возрастанию интенсивности перехода $e 2-h 1$.

Анализ кривых ФЛ проводился при помощи параметрической подгонки формы линии по модели [27]. На рис. 4 стрелками отмечены определенные таким образом энергии переходов, соответствующие краям двумерных квантовых подзон. При переходе от стандартного к инвертированному легированию линии $e 1-h 1$ и $e 2-h 1$ смещаются в сторону меньших энергий. Это связано с увеличением электрического поля в области КЯ, приводящего к росту наклона дна КЯ и уменьшению расстояния между электронными и дырочными уровнями, локализующимися у разных границ КЯ (эффект Штарка для КЯ) $[28,29]$. Также на спектрах ФЛ отчетливо наблюдается увеличение ширины высокоэнергетического пика ФЛ для пар образцов 308/309 и 312/313 при переходе от стандартного к инвертированному легированию. Это коррелирует с увеличением энергии Ферми вырожденного электронного газа в КЯ и соответствующим увеличением ширины энергетической полосы состояний электронов, участвующих в оптических переходах [29-31].

\section{5. Заключение}

Таким образом, показано, что при переходе от верхнего к нижнему $\delta$-легированию кремнием через спейсер приповерхностных КЯ InGaAs/InAlAs происходит заметное повышение плотности электронов в КЯ и проводимости структуры при идентичных составах и толщинах прочих слоев гетероструктуры. Данный эффект объясняется ослаблением обеднения КЯ поверхностными состояниями за счет удаления центроида электронного газа и легирующей области $\delta$-Si от поверхности гетероструктуры на величину, сопоставимую с шириной КЯ. Результаты работы указывают на перспективность использования инвертированных гетероструктур в НЕМТ на основе InGaAs/InAlAs и необходимость оптимизации геометрии слоев для сохранения высокой подвижности электронов в КЯ. Обнаруженные эффекты заметны при глубине залегания КЯ, сравнимой с ее толщиной, и должны становиться тем больше, чем тоньше барьерный слой InAlAs.

Работа выполнена при поддержке РФФИ (грант 16-29-03033 офи_м), Совета по грантам президента РФ (проект МК-2342.2017.2) и Программы конкурентоспособности НИЯУ МИФИ. 


\section{Список литературы}

[1] E.-Y. Chang, C.-I. Kuo, H.-T. Hsu, C.-Y. Chiang, Y. Miyamoto. Appl. Phys. Express, 6, 034001 (2013).

[2] J.A. del Alamo. Nature, 479, 317 (2011).

[3] R. Lai, X.B. Mei, W.R. Deal, W. Yoshida, Y.M. Kim, P.H. Liu, J. Lee, J. Uyeda, V. Radisic, M. Lange, T. Gaier, L. Samoska, A. Fung. Proc. IEDM Tech. Dig. (December 2007) p. 609.

[4] D.H. Kim, J.A. del Alamo, P. Chen, W. Ha, M. Urteaga, B. Brar. Proc. IEDM Tech. Dig. (December 2010) p. 692.

[5] K. Kalna, S. Roy, A. Asenov, K. Elgaid, I. Thayne. Sol. St. Electron., 46, 631 (2002).

[6] Y. Yamashita, A. Endoh, K. Shinohara, M. Higashiwaki, K. Hikosaka, T. Mimura, S. Hiyamizu, T. Matsui. IEEE Electron Dev. Lett., 22, 367 (2001).

[7] D.K. Ferry, J. Ayubi-Moak, R. Akis, N. Faralli, M. Saraniti, S.M. Goodnick. J. Phys.: Conf. Ser., 109, 012001-1 (2008).

[8] X. Zhou, Q. Li, C.W. Tang, K.M. Lau. Appl. Phys. Express, 5, 104201 (2012).

[9] Q. Li, X. Zhou, C.W. Tang, K.M. Lau. IEEE Trans. Electron. Dev., 60 (12), 4112 (2013).

[10] S. Lee, J.J.M. Law, A.D. Carter, B.J. Thibeault, W. Mitchell, V. Chobpattana, S. Krämer, S. Stemmer, A.C. Gossard, M.J.W. Rodwell. IEEE Electron. Dev. Lett., 33 (11), 1553 (2012).

[11] S. Sasa, J. Saito, K. Nanbu, T. Ishikawa, S. Hiyamizu. Jpn. J. Appl. Phys., 23, L573 (1984).

[12] M. Heiblum. J. Vac. Sci. Technol. B, 3, 820 (1985).

[13] N.M. Cho, D.J. Kim, A. Madhukar, P.G. Newman, D.D. Smith, T. Aucoin, G.J. Iafrate. Appl. Phys. Lett., 52, 2037 (1988).

[14] H. Shtrikman, M. Heiblum, K. Seo, D.E. Galbi, L. Osterling. J. Vac. Sci. Technol. B, 6, 670 (1988).

[15] T. Sajoto, M. Santos, J.J. Heremans, M. Shayegan, M. Heiblum, M.V. Weckwerth, U. Meirav. Appl. Phys. Lett., 54, 840 (1989).

[16] T.J. Drummond, H. Morkoc, K.Y. Cheng, A.Y. Cho. J. Appl. Phys., 53, 3654 (1982).

[17] A.S. Brown, R.A. Metzger, J.A. Henige, L. Nguyen, M. Lui, R.G. Wilson. Appl. Phys. Lett., 59, 3610 (1991).

[18] T. Akazaki, J. Nitta, H. Takayanagi, T. Enoki, K. Arai. Appl. Phys. Lett., 65, 1263 (1994).

[19] H. Kunzel, H.G. Bach, J. Böttcher, C. Heedt. J. Vac. Sci. Technol. B, 12, 2910 (1994).

[20] Р.А. Хабибуллин, И.С. Васильевский, Г.Б. Галиев, Е.А. Климов, Д.С. Пономарев, В.П. Гладков, В.А. Кульбачинский, А.Н. Клочков, Н.А. Юзеева. ФТП, 45 (5), 666 (2011).

[21] С. Зи. Физика полупроводниковых приборов (М., Мир, 1984). [Пер. с англ.: S.M. Sze. Physics of Semiconductor Devices (N.Y., Wiley, 1981)].

[22] Р.А. Хабибуллин, Г.Б. Галиев, Е.А. Климов, Д.С. Пономарев, И.С. Васильевский, В.А. Кульбачинский, П.Ю. Боков, Л.П. Авакянц, А.В. Червяков, П.П. Мальцев. ФТП, 47 (9), 1215 (2013).

[23] Г.Б. Галиев, И.С. Васильевский, Е.А. Климов, А.Н. Клочков, Д.В. Лаврухин, С.С. Пушкарёв, П.П. Мальцев. ФТП, 49 (9), 1243 (2015).

[24] S. Adachi. Properties of Semiconductor Alloys: Group-IV, III-V and II-VI Semiconductors (Wiley, 2009).

[25] I. Vurgaftman, J.R. Meyer, L.R. Ram-Mohan. J. Appl. Phys., 89, 5815 (2001).
[26] K. Kajiyama, Y. Mizushima, S. Sakata. Appl. Phys. Lett., 23, 458 (1973).

[27] S.K. Brierley. J. Appl. Phys. 74, 2760 (1993).

[28] H. Brugger, H. Mussig, C. Wolk, K. Kern, D. Heitmann. Appl. Phys. Lett., 59 (21), 2739 (1991).

[29] G.B. Galiev, I.S. Vasilevskii, E.A. Klimov, S.S. Pushkarev, A.N. Klochkov, P.P. Maltsev, M.Yu. Presniakov, I.N. Trunkin, A.L. Vasiliev. J. Cryst. Growth, 392, 11 (2014).

[30] Г.Б. Галиев, Е.А. Климов, А.Н. Клочков, Д.В. Лаврухин, С.С. Пушкарев, П.П. Мальцев. ФТП, 48 (5), 658 (2014).

[31] О.А. Рубан, С.С. Пушкарев, Г.Б. Галиев, Е.А. Климов, Д.С. Пономарев, Р.А. Хабибуллин, П.П. Мальцев. Нанои микросистемная техника, 10, 12 (2013).

Редактор А.Н. Смирнов

\section{Electron properties of near-surface quantum wells InGaAs/InAIAs with inverted doping on InP substrates}

\author{
G.B. Galiev ${ }^{1}$, A.N. Klochkov' ${ }^{1}$, I.S. Vasil'evskii ${ }^{2}$, \\ E.A. Klimov' ${ }^{1}$, S.S. Pushkarev' ${ }^{1}$, A.N. Vinichenko ${ }^{2}$, \\ R.A. Khabibullin ${ }^{1}$, P.P. Maltsev ${ }^{1}$ \\ ${ }^{1}$ Institute of Ultra High Frequency Semiconductor \\ Electronics, Russian Academy of Sciences, \\ 117105 Moscow, Russia \\ ${ }^{2}$ National Research Nuclear University „MEPhl“, \\ 115409 Moscow, Russia
}

Abstract The electron transport properties and optical properties of the heterostructures with near-surface InGaAs/InAlAs quantum well with inverted (under the quantum well) and standard (over the quantum well) $\delta$-doping position are compared. It is shown that inverted doping of heterostructures results in increase of the two-dimensional electron gas concentration in a quantum well as compared to the standard doping plane position with identical layer thicknesses and compositions. The observed features of the low-temperature electron transport (Shubnikov-de Haas oscillations, Hall effect) and photoluminescence spectra were interpreted by band structure modelling. 